\title{
Small-world conservatives and rigid liberals : attitudes towards sharing in self-proclaimed left and right
}

Citation for published version (APA):

Thomsson, K. M., \& Vostroknutov, A. (2016). Small-world conservatives and rigid liberals : attitudes towards sharing in self-proclaimed left and right. Maastricht University, Graduate School of Business and Economics. GSBE Research Memoranda No. 008 https://doi.org/10.26481/umagsb.2016008

Document status and date:

Published: 01/01/2016

DOI:

10.26481/umagsb.2016008

Document Version:

Publisher's PDF, also known as Version of record

\section{Please check the document version of this publication:}

- A submitted manuscript is the version of the article upon submission and before peer-review. There can be important differences between the submitted version and the official published version of record.

People interested in the research are advised to contact the author for the final version of the publication, or visit the DOI to the publisher's website.

- The final author version and the galley proof are versions of the publication after peer review.

- The final published version features the final layout of the paper including the volume, issue and page numbers.

Link to publication

\footnotetext{
General rights rights.

- You may freely distribute the URL identifying the publication in the public portal. please follow below link for the End User Agreement:

www.umlib.nl/taverne-license

Take down policy

If you believe that this document breaches copyright please contact us at:

repository@maastrichtuniversity.nl

providing details and we will investigate your claim.
}

Copyright and moral rights for the publications made accessible in the public portal are retained by the authors and/or other copyright owners and it is a condition of accessing publications that users recognise and abide by the legal requirements associated with these

- Users may download and print one copy of any publication from the public portal for the purpose of private study or research.

- You may not further distribute the material or use it for any profit-making activity or commercial gain

If the publication is distributed under the terms of Article $25 \mathrm{fa}$ of the Dutch Copyright Act, indicated by the "Taverne" license above, 
Kaj Thomsson,

Alexander Vostroknutov

Small-World Conservatives and Rigid Liberals:

Attitudes Towards Sharing in Self-Proclaimed Left and Right

RM/16/008

\section{GSBE}

Maastricht University School of Business and Economics

Graduate School of Business and Economics

P.O Box 616

NL- 6200 MD Maastricht

The Netherlands 


\title{
Small-World Conservatives and Rigid Liberals: Attitudes Towards Sharing in Self-Proclaimed Left and Right*
}

\section{Kaj M. Thomsson ${ }^{\dagger} \quad$ Alexander Vostroknutov Th $^{\ddagger}$}

January 2016

\begin{abstract}
We experimentally explore the way political preferences shape giving behavior. We find no difference in average giving between the Left and the Right in a Dictator game environment. However, we find the reasons for giving to be different. Right-leaning individuals give according to a norm-dependent utility that takes into account the beliefs of the receiver. The behavior of left-leaning individuals is not shaped by such an interaction between norms and beliefs. We conclude that right-wingers choose in accordance with a "small world" view, where giving is shaped by social interaction, while left-wingers appear rigid in their reaction to social context.
\end{abstract}

JEL classifications: C91, C92, D03, D64

Keywords: experimental economics, social norms, liberals, conservatives, sharing

${ }^{*}$ We would like to thank Matthew Embrey, Martin Strobel and the participants of the Maastricht BEELab meeting for great comments. The funds for this study were provided by the Marie Curie Reintegration Grant (FP7-PEOPLE2010-RG). All mistakes are ours.

${ }^{\dagger}$ Department of Economics, Maastricht University, P.O. Box 616, Maastricht 6200 MD, The Netherlands. e-mail: k.thomsson@maastrichtuniversity.nl

${ }^{\ddagger}$ Center for Mind/Brain Sciences, University of Trento, Via delle Regole 101, 38123 Mattarello (TN), Italy. e-mail: a.vostroknutov@unitn.it

$\S$ Corresponding author. 


\section{Introduction}

In 2014 Americans donated $\$ 358$ billion to charity, clearly a considerable amount that can make a substantial difference in the lives of the receivers. A burgeoning literature aims at explaining the motivation of those who donate. In "Who really cares: the surprising truth about compassionate conservatism," Arthur Brooks (2007) empirically explores the personal characteristics associated with greater individual donations to charitable organizations. Brooks concludes that religion, family values and income primarily determine the amount of charitable giving. He also finds a connection between political preferences and the amount donated: conservatives donate more than liberals. He argues that it is not political orientation per se that determines the propensity to donate, but rather deeper personal characteristics that both shape political preferences and the propensity for charitable giving.

Like much of the research on this topic, Brooks' conclusions are based on correlations in large data sets between the personal characteristics of the donors (being religious, having family, being educated etc.) and the size of their donations. In this view, each characteristic influences the donations independently of other characteristics, and the total amount of donations of any person can be determined by the sum of these influences. While perfectly reasonable as a starting point for understanding giving behavior, this type of analysis is unable to explain the reasons underlying donation decisions. More careful studies, with greater control over individuals' decision-environment, are necessary to understand the mental processes that lead to donations to charity, or freely giving away resources in any other way.

Recent research has made some headway towards understanding these mental processes. A recent article by Winterich, Zhang, and Mittal (2012) points towards an important connection between charitable giving and moral judgement, which paves the way for deeper understanding of variation in giving choices through potentially heterogeneous modes of moral reasoning. Studies in social psychology are starting to uncover psychological and physiological mechanisms behind moral judgements and their connection to political views. The Moral Foundations Theory (MFT), advocated by Haidt (2007), posits that conservatives and liberals use different sets of moral foundations to make moral judgements, which subsequently shapes their donation choices (Fowler and Kam, 2007). Heterogeneity in physiological factors, like sensitivity to aversive stimuli and the dominance

of either "emotional" or "cognitive" systems in the brain, seem to modulate the relevance of different 
moral foundations for moral judgement, which helps explain donation choices (Hibbing, Smith, and Alford, 2014; Greene, Nystrom, Engell, and Darley, 2004). Together, these studies suggest that the significant overlap between personal characteristics and political inclinations presented in Brooks (2007) is not coincidental; rather, it likely stems from fundamental psychological and physiological traits that also shape individual choices with respect to charitable contributions and other forms of giving.

In this paper we try to uncover how sharing with strangers depends on self-proclaimed political preferences. We use two versions of a Dictator game to understand the motivations behind sharing. We also elicit the propensity to follow rules (Kimbrough, Miller, and Vostroknutov, 2014), as well as social norms associated with the Dictator games (Krupka and Weber, 2013; Kimbrough and Vostroknutov, 2015). We emphasize the role of social norms and the trade-off in individuals' utility functions between receiving direct benefits from consumption and indirect benefits from behaving in accordance with norms. We developed a simple utility specification, and, based on a combination of this utility model and a synthesis of existing research on both social norms and behavioral differences between individuals with different ideological (political) leanings, we form two hypotheses. Firstly, we hypothesize that a model where the emphasis is on the role of social norms in determining the choices of individuals in dictatorial positions will be better suited to explain the behavior of (selfproclaimed) "right-wingers," compared to their ideological opposites. Secondly, we hypothesize that right-leaning individuals, when they have dictatorial power, will be more sensitive to the beliefs of the receivers about the identity of the dictatorial giver. ${ }^{1}$

We find no difference in the distributions of offers in Dictator games made by self-proclaimed right- and left-wingers. However, we find stark differences in the reasons behind these sharing choices between the two groups. In particular, we find that right-leaning individuals, in making their sharing decisions, respect social norms to a greater extent, and we also find that their choices are modulated by their rule-following proclivity. In addition, right-wingers decrease their contributions when it is uncertain to the receiver where the offer comes from. That is, right-leaning individuals decrease their contributions when the receiver does not know for sure whether the contribution was made by the actual giver or by someone else.

Based on these results, we conclude that right-wingers choose to share in accordance with the so-called "small world" view, meaning that they care about beliefs of others about their rulefollowing, and they share according to what they believe is the social norm. This is consistent with Moral Foundations Theory, which attributes such behavior to possibly innate tendencies to maintain reputation and order (Haidt and Joseph, 2007). On the other hand, the self-proclaimed left-wingers behave in a starkly different way. We find no correlation between the choices of leftwingers and their rule-following propensities. Furthermore, we find rather weak evidence that

\footnotetext{
${ }^{1}$ We use a left-right terminology in our experiments, and we are interested in both a spectrum based on such a terminology and in a conservative-liberal spectrum. In line with the social psychology literature, where these two definitions are used interchangeably, we show that for our subject pool (Western Europe) these two definitions, left-right and liberal-conservative, coincide.
} 
left-wingers respect what they think is a social norm. We also do not find that they decrease their offers when we introduce uncertainty about where (who) the offers come from. In total, these possible motives can explain only small fraction of the variation in the behavior of left-wingers. We conjecture that the left-wingers are more inclined than right-wingers to follow general ideas about redistribution in society.

\section{Related Literature}

In the social psychology literature on political inclinations and sharing there are several experimental studies that are close to ours. Fowler and Kam (2007) look at the differences in Dictator game giving when dictators know whether the receiver is Republican or Democrat (or anonymous). They find that both Republicans and Democrats give more to the receivers of the same party and less to the receivers of the opposite party. Interestingly, subjects without strong association with either Republicans or Democrats give the highest amount when they face anonymous receiver. The authors explain this behavior with Moral Foundations Theory or MFT (e.g., Haidt and Joseph, 2007, and see references below), claiming that the observed behavior is driven by the ingroup/outgroup sentiments. Winterich, Zhang, and Mittal (2012) also use MFT to show that donations to charities increase if the charity cause is aligned with the moral foundations of a particular person. ${ }^{2}$ Dawes, Loewen, and Fowler (2011) study political participation. They use five Dictator games à la Andreoni and Miller (2002) and find that subjects who reveal preference for higher total welfare have higher political participation than subjects who reveal selfish preferences or inequality averse preferences. Finally, Anderson, Mellor, and Milyo (2005) study choices in Public Goods and Trust games and find little evidence for the differences in behavior of self-proclaimed Republicans and Democrats. Chang, Chen, and Krupka (2014) study the connection between social identity and social norms. They use taxation frames in Dictator game to show that social identity and social norms are related. In our study we use much milder difference between Dictator games and do not observe the change in social norms (see below). It should be noted, that our study goes beyond the aforementioned literature. In all papers mentioned above, the authors just find connections between political inclinations and psychological traits (and/or social norms). We try to understand the reason why this difference exists.

In the experimental economics literature, our design is closest to one of Dana, Weber, and Kuang (2007) who study dictator games where receivers are uncertain about whether dictators knew their payoff or not (second treatment). In their design the dictators originally face a choice without uncertainty about the payoffs of the receivers being resolved. Moreover, dictators can choose to resolve this uncertainty if they wish to. This variant of the dictator game is not very good for

\footnotetext{
${ }^{2}$ Haidt (2007) distinguishes five moral foundations: harm, fairness, ingroup, authority and purity. He shows that liberals base their moral judgement on only harm and fairness foundations, whether conservatives use all five to an equal extent.
} 
testing if second order beliefs are at play. Receivers, who understand the game, should have some belief about whether dictator they face has chosen to resolve the payoff uncertainty or not. Thus, dictators should estimate this belief and then calculate what is the probability that receivers put on them choosing knowingly. Dana, Weber, and Kuang (2007) do not try to pinpoint the source of treatment differences in their experiment. However, the second order belief story we propose fits their findings.

In other studies which involve modified dictator games all authors converge to the conclusion that the difference with the control (standard DG) comes from either changes in norms associated with the modified version of the game or from some form of caring about what others think (receiver, audience etc.). Bardsley (2008) and List (2007) find that in a dictator game where it is possible to take money from the receiver the behavior is different even though the standard DG and the modified version are equivalent from the game theoretic perspective. They conclude that the difference comes from the change in norms associated with the two games. Andreoni and Bernheim (2009) explicitly test the model which predicts that the ubiquity of 50-50 split in DG comes from the audience effect (care for second order belief). Dana, Cain, and Dawes (2006) and Lazear, Malmendier, and Weber (2012) study dictator games with the possibility for dictators to abstain from choice and receive a fixed amount of money. Dana, Cain, and Dawes (2006) find that choosing fixed amount of money instead of facing the sharing option is specifically driven by the desire to not look bad in the eyes of the receiver (second order belief). Lazear, Malmendier, and Weber (2012) find the same for the subset of population that they call "reluctant sharers." Overall, we can conclude that all studies we are aware of attribute the behavioral differences between standard and modified dictator games to either norms or second order beliefs. Our results are consistent with these findings. However, we find that heterogeneity in caring about second order beliefs and following social norms can be connected to the psychological traits and political inclinations, something that is not explored in any of the studies mentioned above.

\section{Experimental Design}

The experiment consists of three stages and a questionnaire. In the first stage subjects play single Dictator game (DG). There are two treatments BASE and ASYM which differ only in the type of DG played in the first stage (see details below). In the second stage subjects answer questions about how socially appropriate they consider each action of both types of DG. This is done in order to elicit norms following the procedure of Krupka and Weber (2013). In the third stage subjects choose in an individual rule-following task as described in Kimbrough, Miller, and Vostroknutov (2014). All three stages are incentivized. In the end of the experiment subjects answer questions from Moral Values Questionnaire and are asked a question about their political inclinations. Experiments were conducted in Maastricht University in March-April 2014. Overall, 13 sessions were conducted, 4 
sessions of the BASE treatment and 9 sessions of the ASYM treatment. 372 subjects took part in the experiment. There were no pilots prior to the experiment. No sessions were dropped.

\subsection{Stage 1: Dictator Games}

In Stage 1 subjects are randomly assigned a role of Dictator or Receiver. In the BASE treatment the Dictator game is almost standard: there are 20 tokens, worth 50 cents each. Dictator can allocate some integer amount of tokens to the Receiver, but no more than 10 tokens. ${ }^{4}$ Dictators know that the Receivers will receive the amount they have chosen. In addition, the Receivers are aware that they won't see the amount they got allocated until the end of the experiment. All this is common knowledge to all subjects. ${ }^{5}$

In the ASYM treatment the information is asymmetric and there is a possibility that the computer will make the division instead of the Dictator. First, the subjects are randomly assigned a role of the Dictator or the Receiver. The receivers are told that the amount they receive can come with probability $2 / 3$ from a Dictator and with probability $1 / 3$ from a computer, which uses the distribution of offers from previous experiments with human choices to generate an offer. Given that Dictators cannot send the Receivers more than 10 tokens (as in BASE treatment) this guarantees that Receivers upon receiving an offer cannot tell from whom it came from. ${ }^{6}$ Receivers do not observe the amount received until the end of the experiment.

Dictators in the ASYM treatment are first informed that they are Dictators. However, they are also told that they make their choice only with probability $2 / 3$ and with the rest of the probability the computer makes the choice for them. The uncertainty is resolved in real time. If computer was randomly chosen to choose, then Dictators are informed about this and do nothing. If a Dictator is chosen to make a choice then the Dictator allocates the tokens as in the BASE treatment (no more than 10 tokens). It is emphasized to the Dictators that if they are chosen to allocate the tokens then this amount will be for sure delivered to the Receivers. Dictators are also aware that Receivers cannot distinguish from whom the offer came. All information about the procedure is common knowledge for all subjects.

It might seem like a waste of resources to resolve the uncertainty in the ASYM treatment before the Dictators make their choices (one third of them end up doing nothing). The reason for this is to have only one possible explanation of treatment effect, namely preferences of Dictators over the beliefs of Receivers. If the uncertainty were resolved after the Dictators have chosen we would have a game that cannot be directly compared to the BASE treatment. In this case Dictators will not

\footnotetext{
${ }^{3}$ The difference in number of sessions is due to the amount of data collectable from the two treatments. In the ASYM treatment less subjects chose as Dictators than in the BASE treatment.

${ }^{4}$ This is what differentiates our design from the standard DG. It should be mentioned that Dictators in standard experiments never allocate more than half to the Receiver. We introduce this difference in order for the BASE treatment to be more comparable with the ASYM treatment.

${ }^{5}$ See Appendix E for the detailed instructions.

${ }^{6}$ If Dictators could send more than half they could signal to the Receivers that this is not a computer offer by sending more than half.
} 
be sure what amount of money the Receivers will actually get, which creates the possibility that treatment effect might come from other sources than second order beliefs. For example, the Dictators might calculate the expected amount of money that Receivers would get and change their behavior due to, say, social preferences. In our design, Dictators in both BASE and ASYM treatments play the same game. The only difference between treatments is that in the ASYM treatment Dictators think that Receivers believe that they see the offer from a human with probability two thirds. Thus, any treatment effects are necessarily concerned with this second order belief.

\subsection{Stage 2: Norm Elicitation}

After the Dictator game we employed methods due to Krupka and Weber (2013) to directly elicit norms for the two types of DG games described above. Each subject was presented with a description of a scenario faced by players in both BASE and ASYM Dictator games. Subjects were instructed to rate the "social appropriateness" of various possible actions that the player could take. Their answers were incentivized using a coordination game where we randomly chose one of the hypothetical actions we asked them to rate and paid them $€ 2$ only if their evaluation was the same as the modal evaluation of peers in their experimental session. ${ }^{7}$

\subsection{Stage 3: Rule-Following Task}

After norm elicitations, we conducted a variant of the rule following task due to Kimbrough and Vostroknutov (2015) which measures each individual's propensity to follow rules (or obey the experimenter). In this individual task participants drop balls one-by-one into two baskets: yellow or blue. For each ball in the yellow basket they receive 10 cents and for each ball in the blue basket they receive 5 cents. The instructions explicitly specify that "the rule is to put the balls into the blue basket." Participants have 50 balls to allocate, thus their earnings can vary from $€ 2.5$ (if they did follow the rule) to $€ 5$ (if they did not follow the rule). ${ }^{8}$ Following Kimbrough and Vostroknutov (2015), we use the cost incurred following the rule as a measure of an individual's propensity to follow norms.

The rule-following task is the last incentivized choice stage of the experiment. After subjects allocate all the balls they observe a screen that shows to them how much they won in all three paid stages of the experiment.

\subsection{Questionnaire}

In the end of the experiment subjects are given the Moral Foundations Questionnaire, or MFQ, (Haidt and Joseph, 2004; Graham, Haidt, and Nosek, 2008) and a question about their political

\footnotetext{
${ }^{7}$ See Appendix E for the detailed instructions.

${ }^{8}$ See Appendix E for the detailed instructions.
} 
inclinations. ${ }^{9}$ The question is: "Consider the political situation in the country where you are a citizen. In this country, where would you place yourself ideologically: to the left or to the right of the political center?" There are five answers possible: Left, Center-Left, Center, Center-Right, Right.

\section{Norm-Dependent Utility}

In this section we present a very simple utility specification that illustrates our hypotheses and shows what behavior should be expected in the two treatments. We use the framework of Kimbrough, Miller, and Vostroknutov (2014). Let the choice of the dictator in the Dictator game be $x \in$ $\{10,11, \ldots, 20\}$ (how many tokens she leaves for herself) and $r \in\{b, a\}$ represent the treatment (BASE or ASYM). Then the Dictator's norm-dependent utility can be defined as

$$
U_{i}(x)=\beta_{i} x+\phi_{i} g^{r}(x) .
$$

Here, $\beta_{i} x$ is the personal utility of the Dictator; $g^{r}:\{10,11, \ldots, 20\} \rightarrow[-1,1]$ represents the (commonly known) social appropriateness of action $x$; and $\phi_{i} \geq 0$ is the norm sensitivity parameter of person $i$. Thus, $\phi_{i} g^{r}(x)$ is the part of the utility function that represents the cost (benefit) associated with following (breaking) the norm. ${ }^{10}$ In our experiment we estimate $\phi_{i}$ by means of the rule-following task and we elicit $g^{r}(x)$ for both treatments using the Krupka and Weber (2013) task. ${ }^{11}$ The theoretical abstraction of a social norm we have in mind is that it is unique and commonly known by all subjects. In reality the elicitation of $g^{r}(x)$ will give different results for different subjects. We think of the elicited social appropriateness as subjects' beliefs about what the true norm really is.

Notice that the utility of the Dictator does not depend on anything but her own payoff and the social appropriateness that the Dictator thinks is in place (depending on the treatment). Since in both treatments, whenever a Dictator chooses, she knows what the Responder will get (her offer), her choice should depend only on $g^{r}(x)$. Thus, we should observe treatment differences only if $g^{a} \neq g^{b}$ which can be empirically verified.

To model a second-order belief-caring Dictator we add an additional term to the above utility function. We assume that a Dictator cares about the appreciation of his norm-following choice by the Receiver. ${ }^{12}$ Thus, the more a Dictator follows the norm, the more utility she gets from knowing

\footnotetext{
${ }^{9}$ See Appendix $\mathrm{F}$ for the detailed instructions.

${ }^{10}$ We use the term "norm" in the following sense. The norm is the action which is mostly socially appropriate, or, in other words, the one with the highest value of $g^{r}$.

${ }^{11}$ We cannot directly estimate $\beta_{i}$. However, in Section $\mathrm{D}$ we show how this estimation can be done using the actual choices of the Dictators.

${ }^{12}$ In principle, the Dictator might care about the beliefs of the Receiver for the reasons other than the normfollowing, for example, self-identity (Akerlof and Kranton, 2000; Bénabou and Tirole, 2004). In Section 5 we provide support for our assumption, as we find that exactly the same Dictators whose choice is driven by norms also show different behavior between treatments, and Dictators whose choice is uncorrelated with their norm-following
} 
that the Receiver appreciates it. In the BASE treatment the utility then becomes

$$
U_{i}(x)=\beta_{i} x+\left(\phi_{i}+\gamma_{i}^{b}\right) g^{b}(x)
$$

where $\gamma_{i}^{b} \geq 0$ represents the sensitivity to others' appreciation of own norm-following. In the ASYM treatment, where the Dictator knows that the Receiver thinks the offer came from him only with probability $2 / 3$, the utility becomes

$$
U_{i}(x)=\beta_{i} x+\left(\phi_{i}+\gamma_{i}^{a}\right) g^{a}(x)
$$

Here we assume that $\gamma_{i}^{a}<\gamma_{i}^{b}$ because in the ASYM treatment the Dictator is less sure that the Receiver believes the offer comes from him.

This utility specification predicts that there are two possible sources of treatment effects: 1) different norms associated with the two games and 2) a desire to be appreciated as a norm-follower. The data we collect for each subject (elicited norms and norm-following propensity) potentially allows us to see what might drive the treatment effect. If the norms for the two games are different, we might not be able to tell what the main driving force behind the effect is. However, if norms are the same $\left(g^{a}=g^{b}=g\right)$ the difference between the two treatments can only come from the uncertainty associated with the second-order belief part of the utility. If this is the case, in the ASYM treatment we should see lower offers because the overall coefficient on $g(x)$ is lower than in the BASE treatment. ${ }^{13}$

\section{$5 \quad$ Results}

\subsection{Data Summary}

We begin by pooling subjects into categories Left, Right and Center. Category Left contains all subjects who expressed their political inclination as Left or Center-Left. Category Right includes those who expressed inclination Right and Center-Right and Center contains those subjects who identified themselves as Center.

Table 1 summarizes the data on the amounts sent by the Dictators when they were chosen to decide the amount to send by treatment and Left-Center-Right distinction.

The non-parametric tests reported in Appendix A show that there is no significant difference among the distributions of offers by treatment and category. ${ }^{14}$

propensity do not behave differently between treatments. This would not be the case if the preference over secondorder beliefs had a different nature than appreciation of norm-following.

${ }^{13}$ The optimal choices are lower under the assumption that $g$ is a decreasing function, which is indeed the case for almost all subjects.

${ }^{14}$ Some WMW tests in Appendix A are weakly significant. However, the general direction is in line with our hypotheses. 


\begin{tabular}{llllll}
\hline \hline & Obs & Mean & SE & \multicolumn{2}{c}{$[95 \%$ conf.int. $]$} \\
\hline Left, BASE & 16 & 3.94 & 0.99 & {$[1.82$} & $6.06]$ \\
Center, BASE & 9 & 5.44 & 1.06 & {$[3.01$} & $7.88]$ \\
Right, BASE & 28 & 3.75 & 0.62 & {$[2.47$} & $5.03]$ \\
\hline Left, ASYM & 34 & 4.18 & 0.62 & {$[2.92$} & $5.43]$ \\
Center, ASYM & 23 & 4.39 & 0.75 & {$[2.84$} & $5.94]$ \\
Right, ASYM & 33 & 2.82 & 0.58 & {$[1.64$} & $4.00]$ \\
\hline \hline
\end{tabular}

Table 1: Data summary of the amount sent (in tokens).

Figure 1 shows the distribution of the number of balls put into the blue basket. As can be seen, many subjects do not put anything in the blue basket (it brings half the return of the yellow basket). Nevertheless, around half of the subjects do put some balls there. We cannot reject the null hypothesis of an absence of a difference in the distributions between Left, Center and Right.

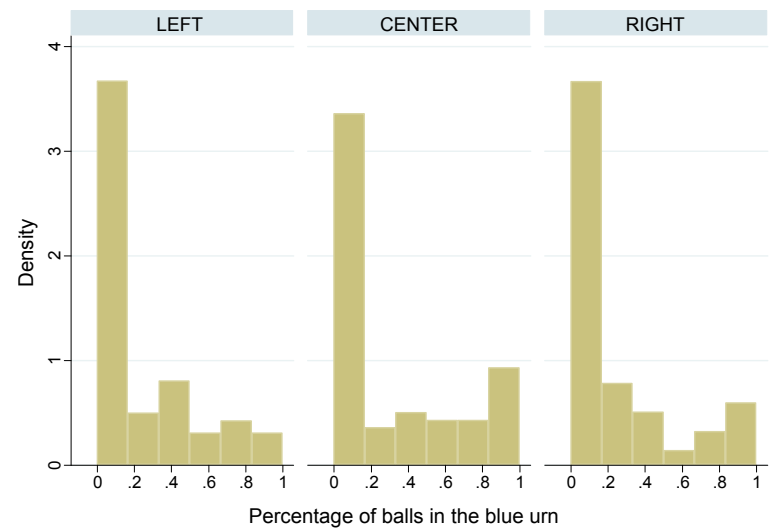

Figure 1: Distribution of the number of balls in the blue basket by Left-Center-Right.

\subsection{Political Inclination and MFQ}

We ask our subjects the question about political inclinations (rate your political affiliation among Left, Center-Left, Center, Center-Right, Right). We find that the self-reported political inclination correlates with the Moral Values elicited through the MFQ. We find harm and fairness being higher among the self-proclaimed Left and authority, purity and ingroup higher among the Right (Figure 2). ${ }^{15}$ This demonstrates that left-right self-proclaimed political inclination in our experiment is consistent with the conservative-liberal spectrum reported in Haidt and Joseph (2007). ${ }^{16}$ Moreover, several studies suggest no cultural differences in moral foundations across many different countries

\footnotetext{
${ }^{15}$ For purity $95 \%$ intervals are not disjoint as for all other characteristics. Nevertheless, the difference is significant.

${ }^{16}$ It should be noted at this point that we do not try to associate the Left with liberal and the Right with conservative. Our data suggests that these classifications are similar and are in line with the studies done in the US. However, it is not the subject of this study to make these comparisons. The purpose of the current analysis is to show that the Left and the Right, as elicited by our questionnaire, are different in psychological traits according to MFQ.
} 
(Graham, Haidt, and Nosek, 2009; Haidt, Koller, and Dias, 1993; Thorisdottir, Jost, Liviatan, and Shrout, 2007). This allows us to assume that the hypotheses tested in many studies in the US can be applied to our subject pool (mostly German and Dutch undergraduates). ${ }^{17}$

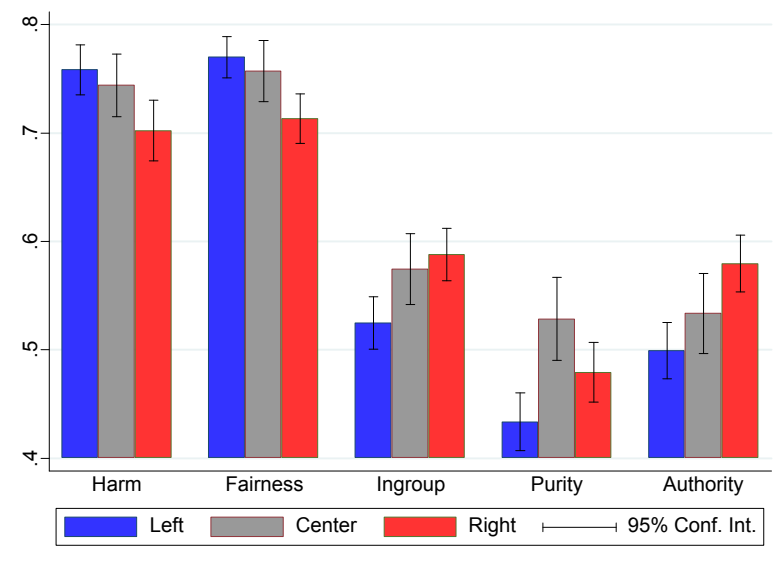

Figure 2: Moral foundation questionnaire and self-reported political inclinations.

The figure in Haidt (2007) (see also Haidt and Graham, 2007) shows that extreme Left deem harm and fairness as much more relevant for moral judgement than ingroup, authority and purity, whereas extreme Right deem all five foundations equally relevant. Haidt (2007) uses data from American colleges. If we compare the relevance of harm and fairness for the Right on Figure 2, we can see that the self-proclaimed Right in our subject pool still consider harm and fairness more relevant than ingroup, authority and purity, which corresponds roughly to "Slightly Conservative" on the figure in Haidt (2007). The difference might be due to a generally more liberal subject pool in the Netherlands than in the American colleges.

We support Figure 2 with some regression analysis. Table 2 reports ordered logit regression of variable polit (equals 0 for Left, 1 for Center-Left, 2 for Center, 3 for Center-Right, 4 for Right) on five traits composed from MFQ questions in Hirsh et al. (2010). ${ }^{18}$ The regression shows that selfreported political inclination corresponds to what Hirsh et al. (2010) call "political orientation" and allows us to predict political inclination from the answers to the Moral Foundations Questionnaire.

As can be seen from the regression, harm and fairness measures decrease the political inclination choice towards Left, while purity and ingroup increase it towards Right.

\footnotetext{
${ }^{17}$ Haidt, Koller, and Dias (1993) and Haidt and Joseph (2007) find that studying in elite American college as well as being well-educated correlates with using only harm and fairness as moral foundations. Our subject pool is similar to that of American elite colleges.

${ }^{18}$ Table 4 in Appendix B explains the variables.
} 


\begin{tabular}{lcc}
\hline \hline polit & 1 & 2 \\
& $\beta / \mathrm{se}$ & $\beta / \mathrm{se}$ \\
\hline harm & $-2.007^{* *}$ & $-1.963^{* *}$ \\
& $(0.983)$ & $(0.896)$ \\
fairness & $-3.185^{* * *}$ & $-3.301^{* * *}$ \\
& $(1.216)$ & $(1.126)$ \\
ingroup & $2.264^{* *}$ & $3.163^{* * *}$ \\
& $(1.086)$ & $(0.820)$ \\
authority & 1.731 & \\
\multirow{2}{*}{ purity } & $(1.362)$ & \\
& $1.308^{*}$ & $1.827^{* * *}$ \\
\hline$N$ & $(0.698)$ & $(0.685)$ \\
\hline \hline
\end{tabular}

Table 2: Ordered logit regression of the self-reported political attitude (Polit $=0$ is left, Polit $=4$ is right) on MFQ. Errors are clustered by session. ${ }^{*}{ }_{-} p<0.1{ }^{* *}-p<0.05$; ${ }^{* * *}-p<0.01$.

\subsection{Elicited Norms}

Figure 3 shows the averages of the norms elicited for the BASE and ASYM treatments. It is clear from the graph that the average norms are very close to each other. One possible question may arise: Do subjects who played the BASE Dictator game report different norms than the subjects who played ASYM Dictator game? The answer is no. The average norms are basically indistinguishable from each other if treated separately for each treatment.

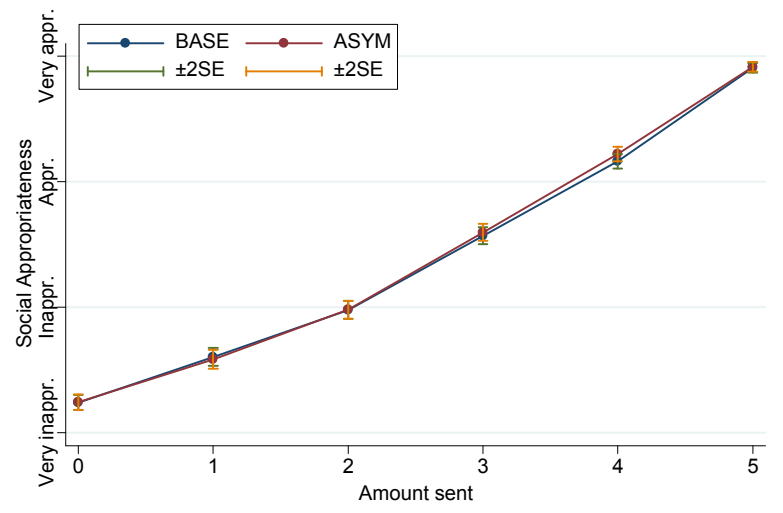

Figure 3: Average norms elicited for BASE and ASYM treatments. All 372 subjects.

This makes us conclude that the norms for the BASE Dictator and ASYM Dictator games are the same. Thus, as was discussed in Section 4 we can assume $g^{a}=g^{b}=g$, which implies that any treatment differences must come from the sensitivity to the second order beliefs. ${ }^{19}$

\footnotetext{
${ }^{19}$ In principle, from the equivalence of averages we cannot directly conclude that the same is true for each subject. However, in comparing two treatments this is not important, since no subject has participated in both treatments. Moreover, the regression analysis below pulls all the data anyway, thus only average norm plays a role eventually.
} 


\subsection{Amount Sent and Norm Following}

In this section we analyze how the rule-following propensity, the expressed norm and the selfreported political inclination influence the amount sent by the Dictators in two treatments. Before we get to the analysis we construct an independent variable that makes sense if we assume that subjects maximize norm-dependent utility as described in Section 4. In the experiment we elicited both an estimate of $\phi$ and an estimate of $g$ for each subject. The question is How can we test if subjects maximize norm-dependent utility? The simplest possibility is to use an estimate of $\phi$ as independent variable. However, we can also use the elicited norm $g$ in order to capture more variance in the data. The idea is to use independent variable $\phi g^{\prime}$, where $g^{\prime}$ stands for the estimate of the derivative of $g$. One may think of $g^{\prime}$ as an estimate of how much each subject thinks others care about him breaking the norm. We estimate $g^{\prime}$ by simply taking the difference between the appropriateness rating for giving half of the pie and the appropriateness rating for giving nothing. ${ }^{20}$ To understand why this is a reasonable variable suppose that $g$ is constant (derivative is zero), then the optimal choice is to maximize personal utility independently of $\phi$ or $g$ (and thus send nothing). ${ }^{21}$ If $g$ instead declines (negative derivative) then we have a trade-off between keeping $€ 1$ (which gives additional personal utility) and sending $€ 1$ (which gives additional norm-following utility). The steeper $g$ is, the more tempting it is to send $€ 1$, especially if $\phi$ is high too. Thus, $\phi g^{\prime}$ should be a good predictor of the amount sent, if it is true that subjects act as if maximizing norm-dependent utility.

Figure 4 shows the average amounts sent by political inclination, treatment and $\phi g^{\prime}$. The amounts sent by the Left and the Center subjects do not seem to depend on $\phi g^{\prime}$. However, for the Right we see a trend: the more subjects are prone to following rules and the steeper their $g$ function is, the more they send. This points towards two different mechanisms behind cooperation in Dictator game for the Left and the Right given our previous observation that the distributions of the amounts sent for the Left and the Right are the same.

Next we look at the regression analysis of the amount sent as dependent on $\phi g^{\prime}$ and treatment. Table 3 shows that there is significant influence of $\phi g^{\prime}$ on the amount sent only for the Right subjects. ${ }^{22}$ For the Left and Center subjects the amount sent does not depend on $\phi g^{\prime}$. This shows that for the Right there is a "homegrown" social norm that is followed when deciding how much to send in the Dictator game while for the Left the mechanism behind giving is different. In addition, we see that there is a treatment effect for the Right subjects. They send around $€ 1.4$ less overall in the ASYM than in the BASE treatment. In the ASYM treatment the presence of asymmetric information makes the second order beliefs of the Receiver less salient, which leads to less giving (see

\footnotetext{
${ }^{20}$ For the vast majority of subjects the norm $g$ is monotonic. In the more complicated analysis of Appendix D we pay more attention to the exact shape of $g$.

${ }^{21}$ Notice that this is true regardless of the level at which $g$ is constant. If one considers all actions equally appropriate, then the personal payoff maximizing one is the optimal choice regardless also of the rule-following propensity.

${ }^{22}$ Table 4 in Appendix B explains the variables.
} 


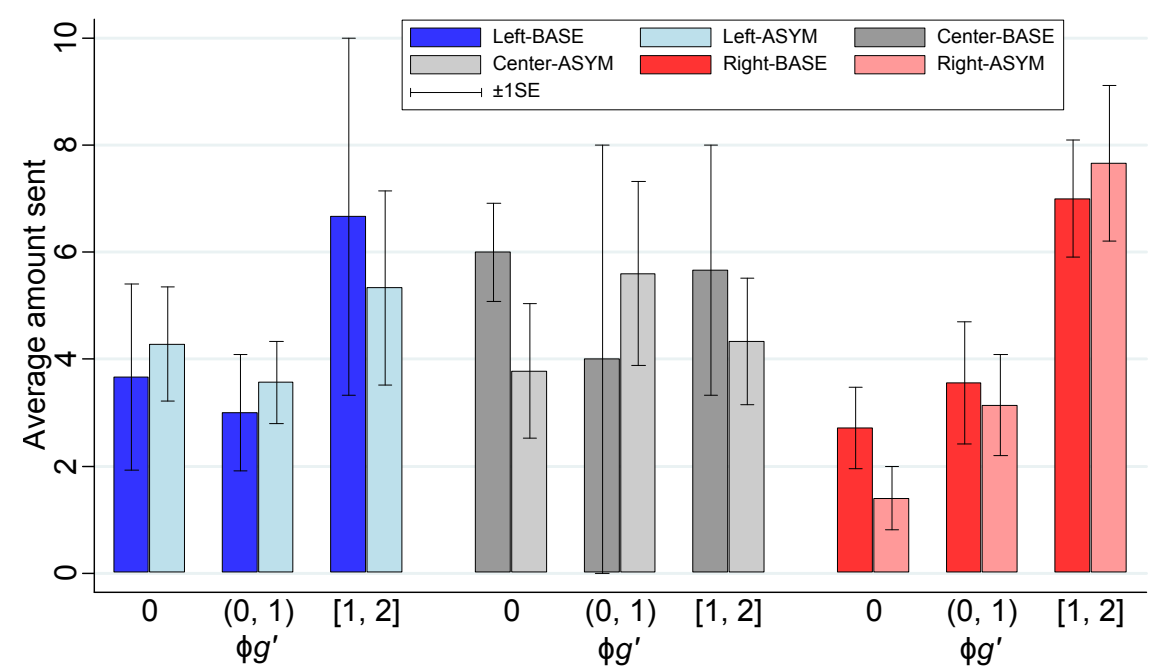

Figure 4: Average amounts sent by self-reported political inclination and treatment as dependent on $\phi g^{\prime}$.

Section 4). The Left and the Center (at least in this model), on the other hand, are not influenced by the information asymmetry, which points towards an idea that they might be using some general idea(s) about welfare and fairness when deciding on the amount to send.

\begin{tabular}{lccc}
\hline \hline Amount Sent & $\begin{array}{c}\text { Left } \\
\beta / \mathrm{se}\end{array}$ & $\begin{array}{c}\text { Center } \\
\beta / \mathrm{se}\end{array}$ & $\begin{array}{c}\text { Right } \\
\beta / \mathrm{se}\end{array}$ \\
\hline$\phi g^{\prime}$ & 0.982 & -0.025 & $2.569^{* * *}$ \\
& $(1.047)$ & $(1.526)$ & $(0.758)$ \\
asym & 0.407 & -1.116 & $-1.448^{*}$ \\
& $(1.035)$ & $(1.667)$ & $(0.771)$ \\
asym $\times \phi g^{\prime}$ & -0.305 & 0.097 & 1.534 \\
& $(1.269)$ & $(2.218)$ & $(0.870)$ \\
cons & $3.505^{* * *}$ & $5.459^{* * *}$ & $2.933^{* * *}$ \\
& $(0.915)$ & $(1.210)$ & $(0.661)$ \\
\hline$N$ & 50 & 32 & 61 \\
$R^{2}$ & .01 & .02 & .34 \\
\hline \hline
\end{tabular}

Table 3: OLS regressions of the amount sent for the Left, the Center and the Right. Errors are clustered by session. ${ }^{*}-p<0.1{ }^{* *}-p<0.05 ;^{* * *}-p<0.01$.

In order to shed some light on how the Left choose we conduct some additional analysis which is presented in Appendix C. We choose to ignore $\phi_{i}$ and regress the amount sent on just $g^{\prime}$. The OLS regression shows that the Left are also sensitive to the norm in the ASYM treatment (interaction is significant) and they also give less in the ASYM treatment. However, this explains only $7 \%$ of the variation in the data. Thus, we conclude that social norms have little influence on left-leaning individuals. ${ }^{23}$ Interestingly, the coefficients for the Right are not significant, which points towards an idea that norm-following propensity $\phi$ is important in the decision making process for the Right.

\footnotetext{
${ }^{23}$ In Section 6 below we discuss other possible explanations of the choices of the Left.
} 
These results are in line with several studies in social psychology. Skitka and Tetlock (1993) report that conservatives tend to not share with people who violate social norms, while liberals help everyone equally (given the availability of the resources). Thorisdottir, Jost, Liviatan, and Shrout (2007) find a connection between rule-following (desire for order) and conservative views in the data set collected in 19 European countries. The treatment effect result for the Right is consistent with the ideas expressed in Haidt (2007). He points out the importance of being a good "intuitive politician," (term coined by Tetlock, 2002) which means being aware of and caring about reputation or, in our terms, second order beliefs. The finding that the Left are not influenced by the beliefs of others suggests that there must be a completely different mechanism behind their choices (for the discussion, see Section 6 below).

The analysis done in this section is rather straightforward. In Appendix D we report more complex analysis of the data. Since we elicit social appropriateness and norm-following propensity for each subject, we are close to having almost all the ingredients of the norm-dependent utility function (except $\beta_{i}$ ). In Appendix D we propose a method for estimating $\beta_{i}$ for each subject. Then, with these estimates at hand we determine what the choice of each subject should be according to the norm-dependent utility, which we now know from the estimates of $g$ and $\phi$. Then we regress the actual choices of our subjects on this predicted choice. The results of this analysis are the same or even stronger than those presented above. That is, the choices of the Right are explained very well by the hypothetical choice that they would have done if they maximized the norm-dependent utility ( $R^{2}$ up to $45 \%$ depending on the specification), while there is no significance at all for the Left.

\section{Discussion}

Our results show that people who self-identify themselves as Right, meaning that they self-identify as right-wing or center-right in the political context of their country, share in accordance with the social norm that they perceive to be the relevant one in the Dictator game. Moreover, they care about others' beliefs: it is important to them that others do not think they are rule-breakers (or norm-breakers). These results are in line with our original hypothesis that the Right behave in accordance with the "small world" perception of social situations.

The norm-based behavior we find for right-leaning individuals may be the result of evolutionary pressure that forced our ancestors to be more cooperative and co-exist in small groups. Haidt and Joseph (2007) argue that adaptive challenges like protecting the young, cooperating with nonkin, cooperating in groups, negotiating hierarchy and avoiding microbes and diseases are the basis of moral foundations (harm, fairness, ingroup, authority, purity) that guide people's decisions, including those related to sharing and charity. However, Graham, Haidt, and Nosek (2009) and Haidt and Graham (2007) point out that, while conservatives consider all five of these foundations equally relevant for moral decisions, liberals deem only two - harm and fairness - relevant.These 
results are also in line with a number of studies which find conservatives to be more sensitive than liberals to the variety of aversive stimuli. The foci of these studies include, among other things, aversive pictures (Dodd et al., 2012; Oxley et al., 2008), negativity bias (Hibbing, Smith, and Alford, 2014), anger (McLean et al., 2014) and disgust (Smith et al., 2011). Based on this, Graham, Haidt, and Nosek (2009) and Haidt and Graham (2007) postulate that conservatism is a more traditional and evolutionarily old ideology, rooted in our species' evolved traits, while liberalism is relatively new and associated with recent Western philosophical ideas.

The dependence on social norms and beliefs of others, when it comes to the sharing choices of the Right in our experiment, fits nicely into this picture. For example, greater sensitivity of conservatives to angry faces (McLean et al., 2014) might lead to an avoidance of making others angry, which in our context implies more giving in the BASE than in the ASYM treatment, exactly what we find. Following social norms might be linked to the desire of conservatives for less uncertainty in their environment (if everyone follows clear cut rules life becomes predictable and orderly), which we interpret as a form of negativity bias against disorder (Hibbing, Smith, and Alford, 2014; Jost, Nosek, and Gosling, 2008). ${ }^{24}$

Compared to the Right, it is more challenging to explain or carefully hypothesize about which mechanisms might be responsible for the sharing choices of the Left. As was mentioned above, liberals tend to use only harm and fairness as their guide to moral decisions, while conservatives consider all five foundations. It is unrealistic to think that liberals are completely devoid of emotion associated with ingroup, authority and purity. More likely, they use a different form of reasoning, more abstract, and potentially greater "cognitive control" when making moral choices. This idea is supported by several studies. In an fMRI study Greene et al. (2004) find two systems in the brain that are active during the resolution of moral dilemmas. The "emotional" system responds quickly to morally "inappropriate" situations, while the "cognitive" system is slower and is involved in controversial settings that involve moral violations. It is possible that the difference between sharing choices of conservatives and liberals lies in the differential involvement of these two systems: conservatives rely perhaps to a greater extent on the emotional system, while the cognitive one might be more prevalent in the decision-making of liberals. In our data we find that subjects who identified themselves as Right chose the offer with in average time of 9.64 seconds (std.err. 1.77) and those who identified themselves as Left chose on average in 14.78 seconds (std.err. 2.98). This provides tentative support for the hypothesis that different forms of reasoning are used when liberals and conservatives make moral choices.

\footnotetext{
${ }^{24}$ A similar connection between being conservative politically and following social norms was made in Skitka and Tetlock (1993) and Thorisdottir, Jost, Liviatan, and Shrout (2007).
} 


\section{Conclusion}

In this paper, we develop a simple theory of sharing behavior, and experimentally explore how sharing in a Dictator game is shaped by political inclination. Based on our theory, and insights from social psychology, we propose that conservatives (or self-proclaimed right-wingers) and liberals (or self-proclaimed left-wingers) reason in fundamentally different ways when deciding how much to share. That is, the mechanisms behind the sharing decisions, though not necessarily the decisions themselves, are fundamentally different between individuals with different political leanings.

We use two versions of the Dictator game: the standard version and a version with incomplete information where the receiver is uncertain about the identity of the sender. More specifically, in the second version of the Dictator game, the receiver believes that she obtains an offer from human only with probability $2 / 3$, while with probability $1 / 3$ the offer is generated by a computer program that sends offers based on the distribution of real offers in past experiments. Importantly, all of this is known to the dictator, which means that we can analyze how this uncertainty at the receiving end affects the dictator's propensity to give. For each subject, we also elicit the rule-following propensity and the social norms associated with each game.

Our findings suggest stark differences between individuals occupying different positions on the political spectrum. We find that self-proclaimed right-wingers, when choosing the amount to share, follow the social norm they believe to be in place, and we also find that they react more strongly to the norm when their rule-following propensity is high. In addition, in what we consider to be perhaps the most novel contribution of the paper, we find that right-wingers also care about the receiver's beliefs: whether the receiver knows where the money comes from (the dictator or a computer program) affects the sharing behavior of right-leaning individuals in our experiments regarding their norm-following behavior. We do not observe similar picture for left-leaning individuals. They do not follow social norms to the same extent and seemingly do not care about the beliefs of others.

These findings are consistent with the so-called Moral Foundations Theory. In our case the results appear to be driven by the desire of the right-wingers to avoid disorder (by following norms) and to maintain reputation (by not making the receiver angry with a small offer). We propose that our findings on the behavior of the political Right may be explained by the "small world" concept. This concept says that right-wing individuals tend to make sharing decisions using moral judgements based on emotions that are evoked by their current social situation, taking into account the reactions of others as if they were living in a small community. Left-wing individuals, on the other hand, appear to use a moral reasoning based abstract ideas regarding redistribution in the society. However, as our theoretical framework appear better equipped to explain the behavior of right-wing individuals, we need - and plan to conduct - more research in order to better understand the mechanisms behind left-wingers' sharing decisions. 


\section{References}

Akerlof, G. A., And R. E. Kranton (2000): "Economics and Identity," Quarterly Journal of Economics, 115(3), 715-753.

Anderson, L. R., J. M. Mellor, and J. Milyo (2005): "Do liberals play nice? The effects of party and political ideology in public goods and trust games," in Experimental and behavioral economics, ed. by J. Morgan, vol. 13 of Advances in Applied Microeconomics, pp. 107-132. Elsevier Ltd.

Andreoni, J., And B. D. Bernheim (2009): "Social Image and the 50-50 Norm: A Theoretical and Experimental Analysis of Audience Effects," Econometrica, 77, 1607-1636.

Andreoni, J., And J. Miller (2002): "Giving According to GARP: An Experimental Test of the Consistency of Preferences for Altruism," Econometrica, 70, 737-753.

BARDSley, N. (2008): "Dictator game giving: altruism or artefact?," Experimental Economics, $11,122-133$.

BÉnabou, R., and J. Tirole (2004): "Incentives and Prosocial Behavior," Discussion papers in economics / Princeton University, Woodrow Wilson School of Public and International Affairs, No. 230.

Brooks, A. C. (2007): Who really cares: The surprising truth about compassionate conservatismAmerica's charity divide - who gives, who doesn't, and why it matters. Basic Books.

Chang, D., R. Chen, and E. Krupka (2014): "Social norms and identity driven choice," mimeo, University of Michigan.

Dana, J., D. M. Cain, and R. M. Dawes (2006): "What you don't know won't hurt me: Costly (but quiet) exit in dictator games," Organizational Behavior and Human Decision Processes, 100, 193-201.

Dana, J., R. A. Weber, And J. X. Kuang (2007): "Exploiting moral wiggle room: experiments demonstrating an illusory preference for fairness," Economic Theory, 33, 67-80.

Dawes, C. T., P. J. Loewen, and J. H. Fowler (2011): "Social Preferences and Political Participation," The Journal of Politics, 73(3), 845-856.

Dodd, M. D., A. Balzer, C. M. Jacobs, M. W. Gruszczynski, K. B. Smith, and J. R. HIBBiNG (2012): "The political left rolls with the good and the political right confronts the bad: connecting physiology and cognition to preferences," Philosophical transactions of the Royal Society of London. B, 367, 640-649.

Forsythe, R., J. L. Horowitz, N. E. Savin, and M. Sefton (1994): "Fairness in Simple Bargaining Experiments," Games and Economic Behavior, 6(3), 347-369.

Fowler, J. H., And C. D. Kam (2007): "Beyond the Self: Social Identity, Altruism, and Political Participation," The Journal of Politics, 69(3), 813-827.

Graham, J., J. Haidt, and B. Nosek (2008): The Moral Foundations Quiz. www.yourmorals.org. 
Graham, J., J. Haidt, and B. A. Nosek (2009): "Liberals and Conservatives Rely on Different Sets of Moral Foundations," Journal of Personality and Social Psychology, 9(5), 1029-1046.

Greene, J. D., L. E. Nystrom, A. D. Engell, and J. D. Darley, John M.and Cohen (2004): "The Neural Bases of Cognitive Conflict and Control in Moral Judgment," Neuron, 44, $389-400$.

Haidt, J. (2007): "The New Synthesis in Moral Psychology," Science, 316, 998-1002.

Haidt, J., And J. Graham (2007): "When Morality Opposes Justice: Conservatives Have Moral Intuitions that Liberals may not Recognize," Social Justice Research, 20(1), 98-116.

Haidt, J., And C. Joseph (2004): "Intuitive ethics: How innately prepared intuitions generate culturally variable virtues," Daedalus, 133(4), 55-66.

Haidt, J., And C. Joseph (2007): "The moral mind: how five sets of innate intuitions guide the development of many culture-specifi c virtues, and perhaps even modules," in The innate mind : structure and contents, ed. by P. Carruthers, S. Laurence, and S. Stich, vol. 3, chap. 19, pp. 367-392. Oxford University Press Inc.: Oxford, UK.

Haidt, J., S. H. Koller, and M. G. Dias (1993): "Affect, Culture, and Morality, or Is It Wrong to Eat Your Dog?," Journal of Personality and Social Psychology, 65(4), 613-628.

Hibbing, J. R., K. B. Smith, and J. R. Alford (2014): "Differences in negativity bias underlie variations in political ideology," Behavioral and Brain Sciences, 37, 297-350.

Jost, J. T., B. A. Nosek, and S. D. Gosling (2008): "Ideology: Its Resurgence in Social, Personality, and Political Psychology," Perspectives on Psychological Science, 3(2), 126-136.

Kimbrough, E. O., J. B. Miller, and A. Vostroknutov (2014): "Norms, Frames and Prosocial Behavior in Games," mimeo, Simon Fraser University, Bocconi University, University of Trento.

Kimbrough, E. O., And A. Vostroknutov (2015): "Norms Make Preferences Social," The Journal of the European Economic Association, forthcoming.

Krupka, E. L., And R. A. WeBer (2013): "Identifying social norms using coordination games: Why does dictator game sharing vary?," Journal of the European Economic Association, 11(3), 495-524.

Lazear, E. P., U. Malmendier, And R. A. Weber (2012): "Sorting in Experiments with Application to Social Preferences," American Economic Journal: Applied Economics, 4(1), 136163.

List, J. A. (2007): "On the Interpretation of Giving in Dictator Games," Journal of Political Economy, 115(3), 482-493.

Mclean, S. P., J. P. Garza, S. A. Wiebe, M. D. Dodd, K. B. Smith, J. R. Hibbing, and K. A. Espy (2014): "Applying the Flanker Task to Political Psychology: A Research Note," Political Psychology, 35(6), 831-840. 
Oxley, D. R., K. B. Smith, J. R. Alford, M. V. Hibbing, J. L. Miller, M. Scalora, P. K. Hatemi, and J. R. Hibbing (2008): "Political Attitudes Vary with Physiological Traits," Science, 321, 1667-1670.

Skitka, L. J., And P. E. Tetlock (1993): "Providing Public Assistance: Cognitive and Motivational Processes Underlying Liberal and Conservative Policy Preferences," Journal of Personality and Social Psychology, 65(6), 1205-1223.

Smith, K. B., D. Oxley, M. V. Hibbing, J. R. Alford, and J. R. Hibbing (2011): "Disgust Sensitivity and the Neurophysiology of Left-Right Political Orientations," PLoS ONE, 6(10).

Tetlock, P. E. (2002): "Social Functionalist Frameworks for Judgment and Choice: Intuitive Politicians, Theologians, and Prosecutors," Psychological Review, 109(3), 451-471.

Thorisdottir, H., J. T. Jost, I. Liviatan, and P. E. Shrout (2007): "Psychological Needs and Values Underlying Left-Right Political Orientation: Cross-National Evidence from Eastern and Western Europe," Public Opinion Quarterly, 71(2), 175-203.

Winterich, K. P., Y. Zhang, and V. Mittal (2012): "How political identity and charity positioning increase donations: Insights from Moral Foundations Theory," International Journal of Research in Marketing, 29, 346-354. 


\section{Appendix (for online publication)}

\section{A Additional Data Summary Analysis}

Figure 5 shows the histograms of the division of the data by treatment and Left-Center-Right category. We run nine Wilcoxon tests to compare distributions on the figures. We compare the distributions of the three groups of subjects inside each treatment and each group between treatments. Only two tests come close to being significant. The Left in ASYM treatment give more than the Right (WMW test, $p=0.1131$, two-sided) and the Center in the ASYM treatment give more than the Right (WMW test, $p=0.0859$, two-sided). If we combine the Left and the Center and compare that to the Right in the ASYM treatment we get more significant results ( $p=0.0561$, two-sided). Thus, Left and Center give more on average (4.26 tokens) than Right (2.82 tokens) in the ASYM treatment. We can also reject the null hypothesis of the same distributions of offers between Left and Right for both treatments (WMW test, $p=0.0667$, twosided). Overall, we do not take these non-parametric tests as the strong evidence of the difference in giving between Left and Right. These results are not unexpected. Anderson, Mellor, and Milyo (2005) also find no significant distinction in the behavior of Democrats and Republicans in Public Goods and Trust games. The pattern of the offers is also very similar to standard Dictator game experiments (e.g., Forsythe et al., 1994).

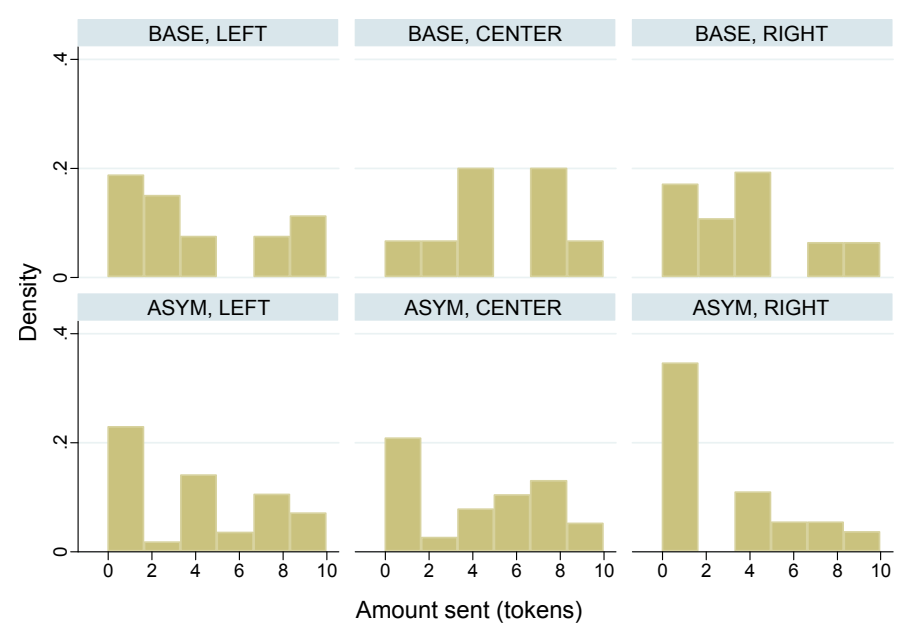

Figure 5: Histograms of the amounts sent by treatment and Left-Center-Right. 


\section{B Variables}

\begin{tabular}{|c|c|c|}
\hline Variable & Range & Definition \\
\hline polit & $\{0,1,2,3,4\}$ & $\begin{array}{l}0 \text { for Left, } 1 \text { for Center-Left, } 2 \text { for Center, } 3 \text { for Center-Right, } 4 \text { for } \\
\text { Right }\end{array}$ \\
\hline harm & {$[0,1]$} & average answer to the 6 questions related to harm from MFQ \\
\hline fairness & {$[0,1]$} & average answer to the 6 questions related to fairness from MFQ \\
\hline ingroup & {$[0,1]$} & average answer to the 6 questions related to ingroup from MFQ \\
\hline authority & {$[0,1]$} & average answer to the 6 questions related to authority from MFQ \\
\hline purity & {$[0,1]$} & average answer to the 6 questions related to purity from MFQ \\
\hline asym & $0 / 1$ & is 1 for ASYM treatment, else 0 \\
\hline$\phi$ & {$[0,1]$} & individual's estimate of $\phi$ (number of balls in the blue basket) \\
\hline$\phi g^{\prime}$ & {$[0,2]$} & $\begin{array}{l}\text { individual's } \phi \text { times the difference in her } g \text { at giving } 0 \text { and giving half } \\
\text { (or derivative) }\end{array}$ \\
\hline maxchoice & {$[0,10]$} & $\begin{array}{l}\text { the amount sent as predicted by the norm-dependent utility maxi- } \\
\text { mization }\end{array}$ \\
\hline
\end{tabular}

Table 4: Variables used in regressions.

\section{Additional Regressions}

\section{C.1 Amount Sent}

\begin{tabular}{llcc}
\hline \hline Amount Sent & $\begin{array}{c}\text { Left } \\
\beta / \mathrm{se}\end{array}$ & $\begin{array}{c}\text { Center } \\
\beta / \mathrm{se}\end{array}$ & $\begin{array}{c}\text { Right } \\
\beta / \mathrm{se}\end{array}$ \\
\hline$g^{\prime}$ & 0.638 & -1.855 & $1.679^{* *}$ \\
& $(0.414)$ & $(1.178)$ & $(0.752)$ \\
asym & $-3.138^{* * *}$ & $-7.082^{* *}$ & 0.033 \\
& $(0.828)$ & $(2.904)$ & $(0.950)$ \\
asym $\times g^{\prime}$ & $1.782^{* *}$ & $3.477^{*}$ & -0.575 \\
& $(0.670)$ & $(1.772)$ & $(0.978)$ \\
cons & $2.901^{* * *}$ & $8.605^{* * *}$ & 0.912 \\
& $(0.364)$ & $(1.095)$ & $(0.703)$ \\
\hline$N$ & 50 & 32 & 61 \\
$R^{2}$ & .07 & .07 & .07 \\
\hline \hline
\end{tabular}

Table 5: OLS regressions of the amount sent for the Left and the Right. Errors are clustered by session. ${ }^{*}-p<0.1 ; * *-p<0.05 ; * * *-p<0.01$. 


\section{Amount Sent and Utility Maximization}

In Section 5 we looked at how the reports of the norm $g$ and estimates of $\phi$ influence the amount sent in Dictator games. However, the analysis was rather simple and did not take into account an important aspect of choice. According to our norm-dependent utility specification each subject maximizes norm-dependent utility and chooses accordingly. In this section we test this hypothesis directly. We have the estimates of (almost) all the ingredients of the norm-dependent utility and thus, we can find what the optimal choice for each subject should be according to the norm-dependent utility specification.

The only problem with such an analysis is the unobserved coefficient $\beta_{i}$ in the personal utility part $\left(\beta_{i} x\right)$. In order to find out how well norm-dependent utility maximization fits the choices that we observe we need to find an estimate of $\beta_{i}$. To make our life harder we postulate that all subjects share the same coefficient $\beta$. Thus, our first task is to find an estimate for $\beta$.

Our idea for how to estimate $\beta$ is to first try to find the individual $\beta_{i}$ that best fits the amount sent, the estimate of $\phi$ and the elicited norm $g$ which we know for each subject. We do it by first taking some value $\tilde{\beta}_{i}$ from the interval $[0,0.1]{ }^{1}$ Then for this $\tilde{\beta}_{i}$ we estimate the norm-dependent utility function $\tilde{u}_{i}(x)=\tilde{\beta}_{i} x+\phi_{i} g_{i}(x)$ for each action $x$ and find the action with the highest utility (for each subject separately). We then find $\tilde{\beta}_{i}$ which best fits the observed amount sent. This procedure gives us an estimate of best fit $\tilde{\beta}_{i}$ for all subjects.

On the next step we find the average $\bar{\beta}$ of $\tilde{\beta}_{i}$ and try to estimate how well the choice under the maximization of the utility $\bar{\beta} x+\phi_{i} g_{i}(x)$ fits our data on the actual amounts sent. To do this we construct an independent variable maxchoice which for each subject is equal to the optimal amount sent if the subject maximized the utility function with $\bar{\beta}$.

From the estimation of the individual $\tilde{\beta}_{i}$ we find that for the Right the average $\bar{\beta}=0.01 .^{2}$ The first two columns of Table 6 show the OLS regressions of the amounts sent for only the Right on the estimated optimal choice given the utility function $0.01 x+\phi_{i} g_{i}(x)$ and treatment interactions. The first column shows all data for the Right and the second column shows the same regression but restricted only to the subjects with $\phi_{i}>0 .^{3}$

One can see that the actual choice is very well predicted by the estimate of the optimal choice under norm-dependent utility maximization. However, if only norm-dependent utility played the role in predicting the behavior in our data we should not observe any treatment effects. This is because the elicited norms should already take into account any treatment effects. Thus, given the fact that the treatment effect is significant, as well as the interaction asym $\times$ maxchoice, we should conclude that there is something else going on in the choices of the Right beyond following the norms. We hypothesize that the negative effect of the treatment (asym coefficient) is due to the difference between ASYM and BASE treatments meaning that the Dictator knows that the Receiver is not sure from whom the offer came from. So, the negative coefficient can be explained by the desire of the Right to not only follow the norm but also to be recognized by others as a norm-follower. In the ASYM treatment Dictators know that Receivers do not necessarily attribute the offer to them, but could also attribute it to the computer, thus they cannot guarantee that the Receiver appreciates their norm-following.

It should be mentioned at this point that for the Left none of the regressions above give any significance with respect to any coefficients. By looking at the histograms of the data we conclude that this is due to the fact that many of the Left who have high $\phi_{i}$ and thus should optimally choose to give half (maxchoice $=10)$ nevertheless choose to give 0 to the receiver. This is true even given that the Dictator game is played

\footnotetext{
${ }^{1}$ In the utility specification $\beta_{i} x+\phi_{i} g_{i}(x)$ the second additive term is calculated in arbitrary units. Thus, in order to make any sense, $\beta_{i}$ should be in some interval so that this relativity is balanced. The interval $[0,0.1]$ was empirically chosen such that for $\beta_{i}=0.1$ the personal part of the utility overwhelms the norm part of the utility.

${ }^{2}$ We take average only over subjects with $\phi_{i}>0$, since for those with $\phi_{i}=0$ any estimate of $\tilde{\beta}_{i}$ is as good as any other in predicting optimal choice.

${ }^{3}$ The reason why we look at only $\phi_{i}>0$ subjects is that if $\phi_{i}=0$, as is true for around half of the subjects, the estimate $\tilde{\beta}_{i}$ can be anything.
} 


\begin{tabular}{lcccc}
\hline \hline & & \multicolumn{3}{c}{$\bar{\beta} / \phi$} \\
Amount Sent & $0.01 /$ all $\phi$ & $0.01 / \phi>0$ & $0.02 /$ all $\phi$ & $0.02 / \phi>0$ \\
Right & $\mathrm{b} / \mathrm{se}$ & $\mathrm{b} / \mathrm{se}$ & $\mathrm{b} / \mathrm{se}$ & $\mathrm{b} / \mathrm{se}$ \\
\hline maxchoice & $0.250^{* * *}$ & $0.241^{* * *}$ & $0.289^{* * *}$ & $0.272^{* *}$ \\
& $(0.044)$ & $(0.064)$ & $(0.028)$ & $(0.091)$ \\
asym & $-1.901^{* *}$ & $-3.066^{* *}$ & $-1.969^{* *}$ & $-2.906^{* *}$ \\
& $(0.842)$ & $(1.229)$ & $(0.796)$ & $(1.057)$ \\
asym $\times$ maxchoice & $0.263^{*}$ & $0.398^{* *}$ & $0.311^{* * *}$ & $0.416^{* * *}$ \\
& $(0.128)$ & $(0.147)$ & $(0.078)$ & $(0.107)$ \\
cons & $2.948^{* * *}$ & $3.018^{* *}$ & $3.007^{* * *}$ & $3.162^{* *}$ \\
& $(0.718)$ & $(1.102)$ & $(0.720)$ & $(1.033)$ \\
\hline$N$ & 61 & 33 & 61 & 33 \\
$R^{2}$ & .30 & .31 & .39 & .45 \\
\hline \hline
\end{tabular}

Table 6: OLS regression of the amount sent on the estimate of the optimal choice for Right. Errors are clustered by session. ${ }^{*}-p<0.1 ; * *-p<0.05 ; * * *-p<0.01$.

before the rule following task.

Next we perform a somewhat different calculation. We take some $\tilde{\beta}_{i} \in[0,0.1]$. For this $\tilde{\beta}_{i}$ we sum over all Right subjects the square deviations of optimal choices given $\tilde{\beta}_{i}$ from the actual choices. Then we find $\tilde{\beta}_{i}$ which minimizes this sum. This can be thought of as non-linear least squares estimation. We find that with this procedure the optimal $\beta$ is 0.05 .

Finally, we perform one more exercise. We take different values of $\bar{\beta}$ and run the regressions analogous to those in the first two columns of Table 6 . Then we check which $\bar{\beta}$ fits our data the best. It turns out that the best value of $\bar{\beta}$ (according to the $R^{2}$ criterion) is $\bar{\beta}=0.02$. The two regressions with 0.02 are shown in the columns 3 and 4 of Table 6 . One can see that for Right subjects with positive $\phi_{i}$ we have $R^{2}=0.45$, which is rather high. 


\section{E Instructions}

\section{General information}

You are participating in a decision making experiment which consists of two parts and a questionnaire. If you follow the instructions carefully, you can earn a considerable amount of money depending on your decisions, the decisions of the other participants and random events. Your earnings will be paid to you in cash at the end of the experiment.

This set of instructions is for your private use only. During the experiment you are not allowed to communicate with anybody. In case of questions, please raise your hand. Then we will come to your seat and answer your questions. Any violation of this rule excludes you immediately from the experiment and all payments. The EU Marie Curie initiative has provided funds for conducting this experiment.

\section{E.1 Stage 1: Dictator Game BASE Treatment}

In this part of the experiment, there will be two types of people, Red and Blue. Throughout Part 1, you will be either a Red person or a Blue person depending on a random choice by the computer. You will be paired with a person of the other type.

You will interact with only one other person in the room. In this experiment a Blue person makes a choice and a Red person does not choose. The amount of money you receive depends on the decision made by the Blue person in your pair. The tokens that you receive in this part of the experiment (translated into Euro) will be paid to you in the end of the experiment. The future tasks in the experiment will not affect your earnings in this part.

\section{Instructions for Blue People}

Each Blue person begins with 20 tokens. Each token is worth 50 cents. Thus, 20 tokens translate into 10 Euro. A Blue person chooses how to allocate these tokens between him/herself and a Red person he/she is paired with. To specify an allocation, the Blue person should type the number of tokens he/she wants to allocate to him/herself and the number of tokens he/she wants to allocate to the Red person and then click "OK." There are two restrictions on the allocation of tokens that the Blue person can choose:

1. The Blue person can allocate only up to 10 tokens to the Red person;

2. The two chosen amounts must sum up to 20 tokens.

\section{Instructions for Red People}

The Red person does not make any decisions. If you are randomly chosen to be the Red person, you will see a screen that informs you about it.

You will not be informed about the number of tokens that the Blue person allocated to you until the end of the experiment.

\section{E.2 Stage 1: Dictator Game ASYM Treatment}

In this part of the experiment, there will be two types of people, Red and Blue. Throughout Part 1, you will be either a Red person or a Blue person depending on a random choice by the computer.

You will be paired with a person of the other type.

You will interact with only one other person in the room. In this experiment the Blue person is randomly selected with some probability to make a choice and the Red person does not choose. The amount of money you receive depends on the decision made by the Blue person in your pair or the Computer. The tokens 
that you receive in this part of the experiment (translated into Euro) will be paid to you in the end of the experiment. The future tasks in the experiment will not affect your earnings in this part.

\section{Instructions for Blue People}

Each Blue person begins with 20 tokens. Each token is worth 50 cents. Thus, 20 tokens translate into 10 Euro. With probability $2 / 3$ the Blue person is chosen to allocate these tokens between him/herself and a Red person he/she is paired with. With probability $1 / 3$ the allocation is performed by the Computer (Computer decides how many tokens both Blue and Red persons get), in which case the Blue person does not make any decision.

If the Blue person is chosen to allocate the tokens, he/she should type the number of tokens that he/she wants to allocate to him/herself and the number of tokens he/she wants to allocate to the Red person and then click OK.

There are two restrictions on the allocation of tokens that the Blue person can choose:

1. The Blue person can allocate only up to 10 tokens to the Red person;

2. The two chosen amounts must sum up to 20 tokens.

If the Blue person is not chosen to allocate the tokens, then the Computer decides on the allocation of tokens to Blue and Red persons. The Computer determines the allocation by a random draw from the set of allocations obtained from analogous experiment in the past in which other participants made decisions. Therefore, the choice of the Computer is the same as the choice of some (human) participant in the past. The Computer is bound by the same rules: it never allocates more than 10 tokens to the Red person and the sum of tokens allocated to Blue and Red persons is 20 tokens.

The Red person will NOT be informed who (the Blue person or the Computer) has made the choice. The Red person will only observe the number of tokens allocated to him/her.

In case the Blue person is not chosen to decide, he/she will only see the number of tokens allocated to him/her by the Computer in the end of the experiment.

\section{Instructions for Red People}

The Red person does not make any decisions. If you are randomly chosen to be the Red person, you will see a screen that informs you about it. You will not be informed about the number of tokens that the Blue person or the Computer allocated to you until the end of the experiment. You will not be informed about whether the Blue person or the Computer allocated the tokens to you. You will only observe the number of tokens you received.

\section{E.3 Stage 2: Norm Elicitation}

\section{Questionnaire 1}

After the task described on the previous page you will be asked to give answers to a series of questions. On your screen, you will read descriptions of a series of situations. These descriptions correspond to situations in which one person, Individual A, must make a decision. For each situation, you will be given a description of the decision faced by Individual A. This description will include several possible choices available to Individual A. After you read the description of the decision, you will be asked to evaluate the different possible choices available to Individual A and to decide, for each of the possible actions, whether taking that action would be socially appropriate and consistent with moral or proper social behavior or socially inappropriate and inconsistent with moral or proper social behavior. By socially appropriate, we mean behavior that most people agree is the correct or ethical thing to do. Another way to think about what we mean is that if Individual A were to select a socially inappropriate choice, then someone else might be angry at Individual A for doing so. In each of your responses, we would like you to answer as truthfully as possible, based on your opinions of what constitutes socially appropriate or socially inappropriate behavior. 
To give you an idea of how to answer these questions, you will first go through an example. The example situation will appear on your screen right after you finish the first task described on the previous page. Please go through the example carefully and raise your hand if you have any questions.

When answering the questions in the three hypothetical situations that follow the example you can earn 2 Euro. In particular, one of the questions will be chosen randomly after everyone in the room has finished with all three situations. You receive 2 Euro if you answered the randomly chosen question in the same way as the majority of participants in the room. If your answer is different from the answer that the most participants in the room have given, then you get nothing.

\section{E.4 Stage 3: Rule-Following Task}

In Part 2 of this experiment, you will decide how to allocate 50 balls between two buckets. Your task is to put each ball, one-by-one, into one of the two buckets: the blue bucket or the yellow bucket. The balls will appear in the center of your screen, and you can allocate each ball by clicking and dragging it to the bucket of your choice.

For each ball you put in the blue bucket, you will receive 5 Euro cents, and for each ball you put in the yellow bucket, you will receive 10 Euro cents.

The rule is to put the balls in the blue bucket.

Once the experiment begins, you will have 10 minutes to put the balls into the buckets. When you are finished, please wait quietly until the end of the 10-minute period.

Your payment from Part 2 will be based on your decisions: it is the sum of payments from the blue and yellow buckets.

This is the end of the instructions for Part 2. If you have any questions, please raise your hand and an experimenter will answer them privately. Otherwise, please wait quietly for the experiment to begin. 


\section{F Moral Foundations Questionnaire}

Part 1. When you decide whether something is right or wrong, to what extent are the following considerations relevant to your thinking? Please rate each statement using this scale:

\begin{tabular}{cccccc}
\hline 0 & 1 & 2 & 3 & 4 & 5 \\
\hline not at all relevant & not very relevant & slightly relevant & somewhat relevant & very relevant & extremely relevant \\
\hline
\end{tabular}

1. Whether or not someone suffered emotionally

2. Whether or not some people were treated differently than others

3. Whether or not someone's action showed love for his or her country

4. Whether or not someone showed a lack of respect for authority

5. Whether or not someone violated standards of purity and decency

6. Whether or not someone was good at math

7. Whether or not someone cared for someone weak or vulnerable

8. Whether or not someone acted unfairly

9. Whether or not someone did something to betray his or her group

10. Whether or not someone conformed to the traditions of society

11. Whether or not someone did something disgusting

12. Whether or not someone was cruel

13. Whether or not someone was denied his or her rights

14. Whether or not someone showed a lack of loyalty

15. Whether or not an action caused chaos or disorder

16. Whether or not someone acted in a way that God would approve of

Part 2. Please read the following sentences and indicate your agreement or disagreement:

\begin{tabular}{cccccc}
\hline 0 & 1 & 2 & 3 & 4 & 5 \\
\hline Strongly Disagree & Moderately Disagree & Slightly Disagree & Slightly Agree & Moderately Agree & Strongly Agree \\
\hline
\end{tabular}

1. Compassion for those who are suffering is the most crucial virtue.

2. When the government makes laws, the number one principle should be ensuring that everyone is treated fairly.

3. I am proud of my countrys history.

4. Respect for authority is something all children need to learn.

5. People should not do things that are disgusting, even if no one is harmed.

6. It is better to do good than to do bad.

7. One of the worst things a person could do is hurt a defenseless animal. 
8. Justice is the most important requirement for a society.

9. People should be loyal to their family members, even when they have done something wrong.

10. Men and women each have different roles to play in society.

11. I would call some acts wrong on the grounds that they are unnatural.

12. It can never be right to kill a human being.

13. I think its morally wrong that rich children inherit a lot of money while poor children inherit nothing.

14. It is more important to be a team player than to express oneself.

15. If I were a soldier and disagreed with my commanding officers orders, I would obey anyway because that is my duty.

16. Chastity is an important and valuable virtue.

*The Moral Foundations Questionnaire (full version, July 2008) by Jesse Graham, Jonathan Haidt, and Brian Nosek. For more information about Moral Foundations Theory and scoring this form, see: www.MoralFoundations.org 


\section{Moral Foundations Questionnaire: 30-Item Full Version Item Key, July 2008}

-Below are the items that compose the MFQ30. Variable names are IN CAPS

-Besides the 30 test items there are 2 catch items, MATH and GOOD

-For more information about the theory, or to print out a version of this scale formatted for participants, or to learn about scoring this scale, please see: www.moralfoundations.org

PART 1 ITEMS (responded to using the following response options: not at all relevant, not very relevant, slightly relevant, somewhat relevant, very relevant, extremely relevant)

MATH - Whether or not someone was good at math [This item is not scored; it is included both to force people to use the bottom end of the scale, and to catch and cut participants who respond with last 3 response options]

\section{Harm:}

EMOTIONALLY - Whether or not someone suffered emotionally

WEAK - Whether or not someone cared for someone weak or vulnerable

CRUEL - Whether or not someone was cruel

\section{Fairness:}

TREATED - Whether or not some people were treated differently than others

UNFAIRLY - Whether or not someone acted unfairly

RIGHTS - Whether or not someone was denied his or her rights

Ingroup:

LOVECOUNTRY - Whether someones action showed love for his or her country

BETRAY - Whether or not someone did something to betray his or her group

LOYALTY - Whether or not someone showed a lack of loyalty

Authority:

RESPECT - Whether or not someone showed a lack of respect for authority

TRADITIONS - Whether or not someone conformed to the traditions of society

CHAOS - Whether or not an action caused chaos or disorder

Purity:

DECENCY - Whether or not someone violated standards of purity and decency

DISGUSTING - Whether or not someone did something disgusting

GOD - Whether or not someone acted in a way that God would approve of 
PART 2 ITEMS (responded to using the following response options: strongly disagree, moderately disagree, slightly disagree, slightly agree, moderately agree, strongly agree)

GOOD It is better to do good than to do bad. [Not scored, included to force use of top of the scale, and to catch and cut people who respond with first 3 response options]

\section{Harm:}

COMPASSION - Compassion for those who are suffering is the most crucial virtue.

ANIMAL - One of the worst things a person could do is hurt a defenseless animal.

KILL - It can never be right to kill a human being.

Fairness:

FAIRLY - When the government makes laws, the number one principle should be ensuring that everyone is treated fairly.

JUSTICE Justice is the most important requirement for a society.

RICH - I think its morally wrong that rich children inherit a lot of money while poor children inherit nothing.

Ingroup:

HISTORY - I am proud of my countrys history.

FAMILY - People should be loyal to their family members, even when they have done something wrong. TEAM - It is more important to be a team player than to express oneself.

Authority:

KIDRESPECT - Respect for authority is something all children need to learn.

SEXROLES - Men and women each have different roles to play in society.

SOLDIER - If I were a soldier and disagreed with my commanding officers orders, I would obey anyway because that is my duty.

Purity:

HARMLESSDG - People should not do things that are disgusting, even if no one is harmed.

UNNATURAL - I would call some acts wrong on the grounds that they are unnatural.

CHASTITY - Chastity is an important and valuable virtue. 